\title{
Geographical and Territorial Vision Facing the Crisis
}

\author{
Maria Prezioso
}

Published online: 14 May 2013

(C) CEEUN 2013

\begin{abstract}
Taking inspiration from the ideas of Kitson et al. (Camb J Econ Reg Soc 4:289-302, 2011) and other authors Pettifor (The coming first world debt crisis. Palgrave, London, 2006) and Rodriguez-Pose (Econ Geogr 86:361-370, 2010), the paper analyzes and discusses the so defined Geographies of Austerity in front of the current crisis. The resulting critical considerations suggest to adopt rigorous measures rather than austerity measures, in order to not invalidate the development efforts implemented by states and regions. Discussions are also directed to that part of the European and Italian economic and political Geography that used traditional tools to read economic trends in a strongly territorialized key. The lack of participation of the economic Geography to European public policies affected especially the 2007-2013 programming that mainly focused on boosting competitiveness in the global market. These considerations are discussed to investigate the causes which hindered to take significant preventive measures, as in the case of Italy. Different and "sustainable" solutions can come from several spatial approaches and baseline scenarios based on uncertain economic forecasts that economic and political geography has produced in Europe.
\end{abstract}

Keywords Geography of Rigor · Cohesion · Place-based evidences · Regional development · Competitiveness in sustainability

\section{What Economists Do Not See and Then Do Not Say?}

In a recent article published in the Journal of Economy and Society Regions, Kitson et al. (2011) analyze the so defined Geographies of Austerity.

Maria Prezioso is full Professor of Economic Geography.

M. Prezioso ( ()

Department of Sciences, Technology and Education,

University of Rome "Tor Vergata", Rome, Italy

e-mail: maria.prezioso@uniroma2.it 
The Authors represent the current crisis as an inevitable result of an economical optimistic view that pervaded the market and the politics in the past decade (mainly British and American). This new vision is based on confidence in new technologies and on the activism of a particularly creative politic class, without taking into account the lack of prudence of the states in the financial field. In this way, the European support to policies of "sustainable growth" (the post-Lisbon and the postGothenburg) stressed this optimism until 2009.

The same Authors admit that only few opinions were raised to alarm on what was happening (Pettifor 2006). Only a very small number of geographical contributions (Prezioso 2006a) do not adopt deductive and spatial approaches and visions based on uncertain economic forecasts.

Taking inspiration from the ideas of Kitson, Martin and Tyler on the return to austerity measures and their impact, the article examines the motivations that led to the crisis and the reason why this crisis could have been imagined in advance. This prevision should have been helped by the large number of visions, tools and reliable scenarios that economic and political geography has produced in Europe (ESPON 2006, 2013).

The resulting critical considerations suggest to adopt rigorous measures rather than austerity measures, in order to not invalidate the development efforts implemented by states and regions. Discussions are also directed to that part of the European and Italian economic and political Geography that used traditional tools to read economic trends in a strongly territorialized key. Moreover, those tools were used to assess the political, economic and the social impacts that would follow from the disruption of the economic policy of the "state guide" that is the US, ensuring the European economic balance besides the world economic one.

The lack of participation of the economic Geography to public policies, in particular to the European ones (Martin 2001; Rodriguez-Pose 2010), affected especially the 2007-2013 programming that mainly focused on boosting European competitiveness in the global market. In this occasion, it should have been taken into account that the European position in the world was changing (Grasland 2007; Van Hamme 2012), not only because of the new market challenges that came from Asian countries, but also due to the new conditions of an aging workforce, the changing demographics, energy problems, climate change, etc.

This is one of the causes which hindered to take preventive measures, as in the case of Italy, and to be significant to address towards different and "sustainable" solutions.

Many commentators of the crisis refer that the first signals ascend from the 80's and 90's of the last century, and others, more realistically, from the end of the Vietnam War. In this period, the US could not ensure the maintenance of the Bretton Woods agreements, crippling, after thirty years, the very reason on which the "state guide" bears. Therefore, also the persistence of a keynesian balanced model, designed to support depressive phases in situations of conflict, was put under discussion.

Since 2001, the participation of Europe and United States to the conflicts in Afghanistan and in the Middle East has destroyed a significant part of the European national economies. This situation reduced that part of the GDP assignable to 
reforms required by markets and international investors, triggering a structural and confidential crisis. It is well known how much these items of costs affect the budgets of the states participating in conflicting events, without generating profits or returns, making Bilmes and Stiglitz (2006) affirm that "war economies" destroy economies.

Keynes's theory and the neo-keynesians are back to the top of the European Economic scene, offering addresses and solutions (financial more than political) that would set aside the budget and spending review issues in favor of further increases of public spending (Krugman 2008 for all).

Economists, stakeholders, opinion leaders, European and American policy makers adapt to this vision. Looking at the crisis from a mainly national and local point of view, as evidenced by rumors on the instability of governments (including the technical ones), on the end of politics, on the role of banks, etc., they missed to clarify the impact that choices on growth could generate (even if smart) in the medium/long-term on the European macro-economic system and on its relative territorial dimensions.

The roots of the place-based crisis do not get the attention of press and media: they are only discussed in "niche" seminars and they do not have room in the financial debate. Nevertheless, they open a new request of economic and political geographies, based-today more than ever-on the understanding of the regional and local potential development, crucial to the beginning of an European action, in the 2014-2020 programming perspective, that aims to rigorous and active operation, not only to austerity.

As explicitly requested by the Commission and by the DG Regio Policy (Monfort 2011; Dijkstra 2011), the focus of many discussions since 2006 is the rigor of the economic-territorial action of states and regions (ESPON 2006, 2013). With the fundamental contribution of Geography, this severity has been reflected in the offer of solutions and tools, including the most recent EU reports (ESPON Program 2013), interpreting international, national and regional trends in a different way. Presenting the V Cohesion Report in 2011, L. Dijkstra stressed the need to align the future cohesion policy to the Europe2020 aims and to concentrate funds on less developed regions, also referring to banking investments.

The geographical key to understanding crisis and its antecedents (Prezioso 2006a, b, 2008a, b, c), mainly of the territorial ones, expressed "from below" in a pervasive way. Portugal, Ireland, Greece, Spain (PIGS) and Italy (PIIGS), showed a rising inflation, business, productivity and employment crisis, higher costs, etc. The European Commission, the European Central Bank, the European Investment Bank, the International Monetary Fund (IMF) and, in particular, the countries of the Pentagon, gave no explicit attention to the problem as everything seemed to depend on a lack of competitiveness.

In 2008-2009, the OECD (2008 the OECD database contains 40 indicators with an increasing graduality of territorialism) and the Barca Report (Barca 2009) still pushed to a reflection the European policies that doesn't recognize a territorial perspective but only a "spatial" one to the crisis and to its performance, reducing the economies to the immobility of austerity.

The "crisis" appeared as a possible and identifiable vision since 2004-2007, measured as the negative of the territorial cohesion (Figs. 1, 2): "The concept of 


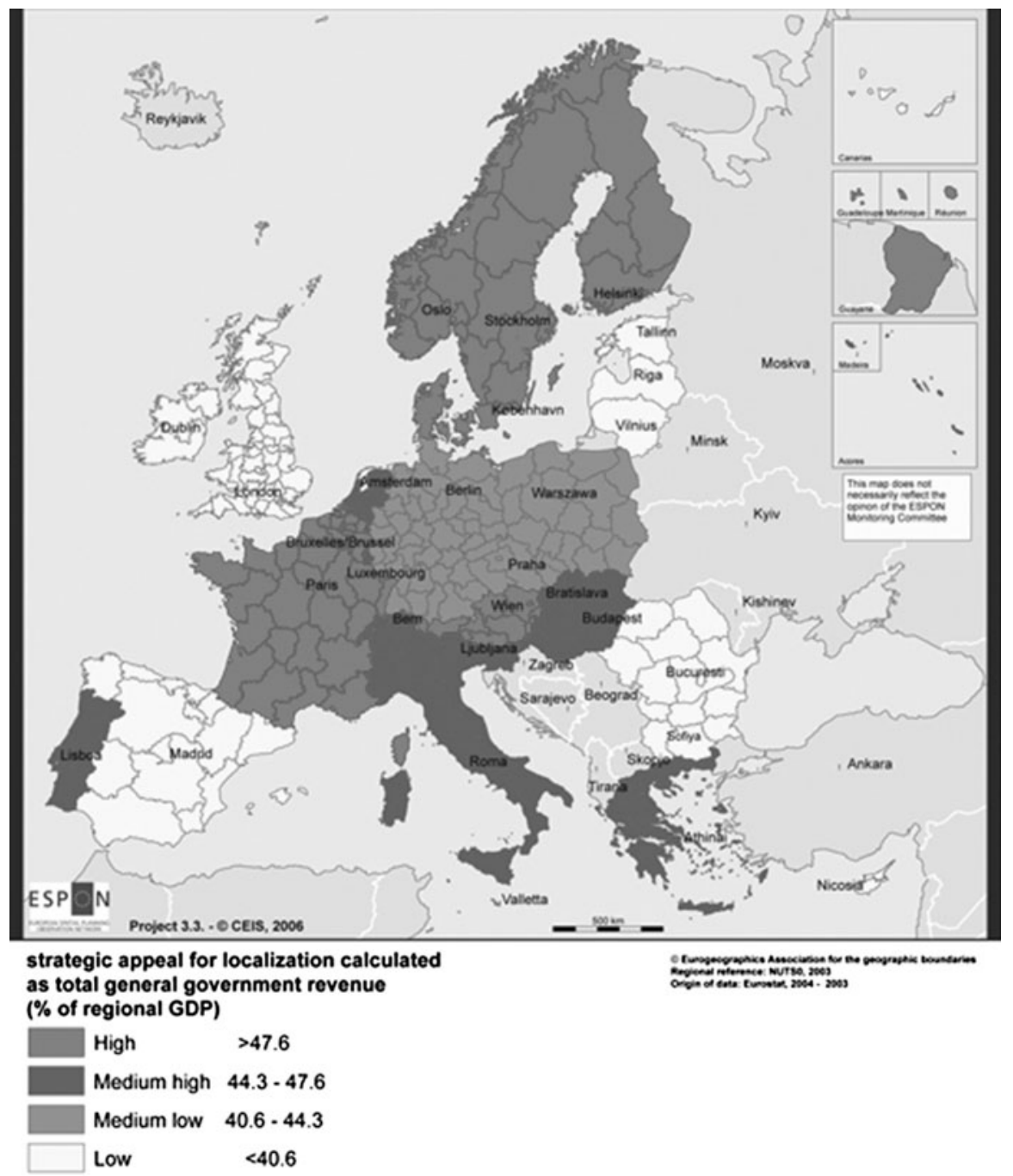

Fig. 1 Distribution of the tax burden in Europe (Prezioso 2006a)

territorial cohesion extends beyond the notion of economic and social cohesion by both adding to this and reinforcing it. In policy terms, the objective is to help achieve a more balanced development by reducing existing disparities, avoiding territorial imbalances and by making both sectorial policies which have a spatial impact and regional policy more coherent. The concern is also to improve territorial integration and encourage co-operation between regions." (European Commission's Third Report on Economic and Social Cohesion 2004).

In that period, it was already possible to assess the impact and the medium-long term results of an economic cycle that started under the presidency of Greece in 2003. Moreover, there was the chance to assess the lack of cohesion in each region 


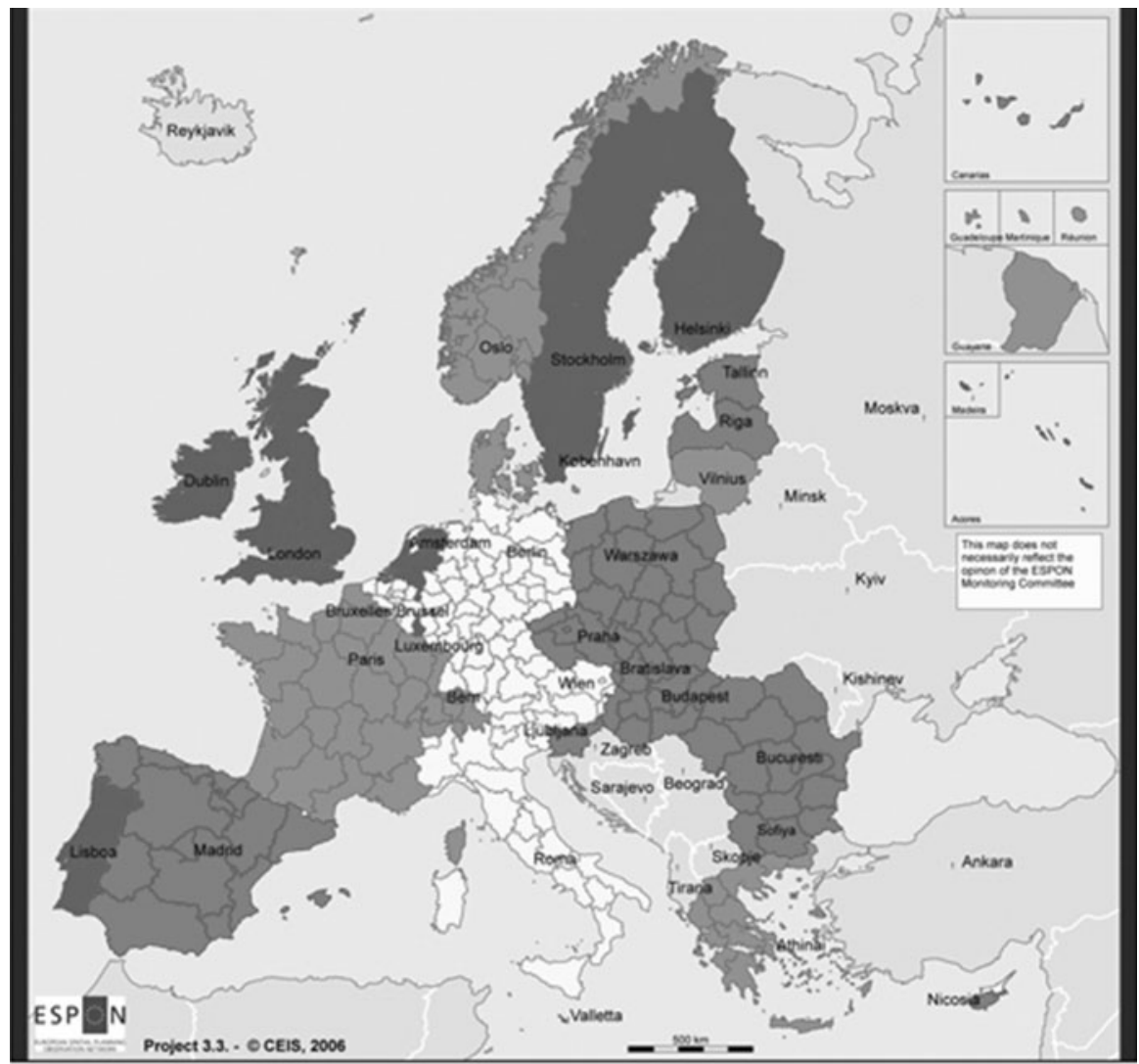

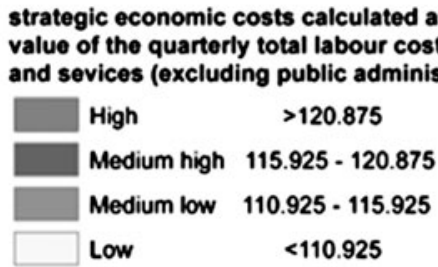

Fig. 2 Distribution of labor cost in Europe (Prezioso 2006a)

in order to concentrate the Structural Funds on those areas, the so-called legging regions.

The anticipated entry of new Member States into the European Union in 2004 has been perceived as a European decisive political choice in opposition to the aggression of the emerging economies (China and India) to the after Maastricht European market. This entrance has also been considered poorly influential on the overall performance of the European economy, even if the employment rate in Spain, in Greece and in parts of Italy was very low (Fig. 3) and the progressive aging of the population, not only in Italy, Spain, Greece (a rate of over $3 \%$ per year) but also, to a lesser extent, in Germany, Denmark, Switzerland, was already evident. 


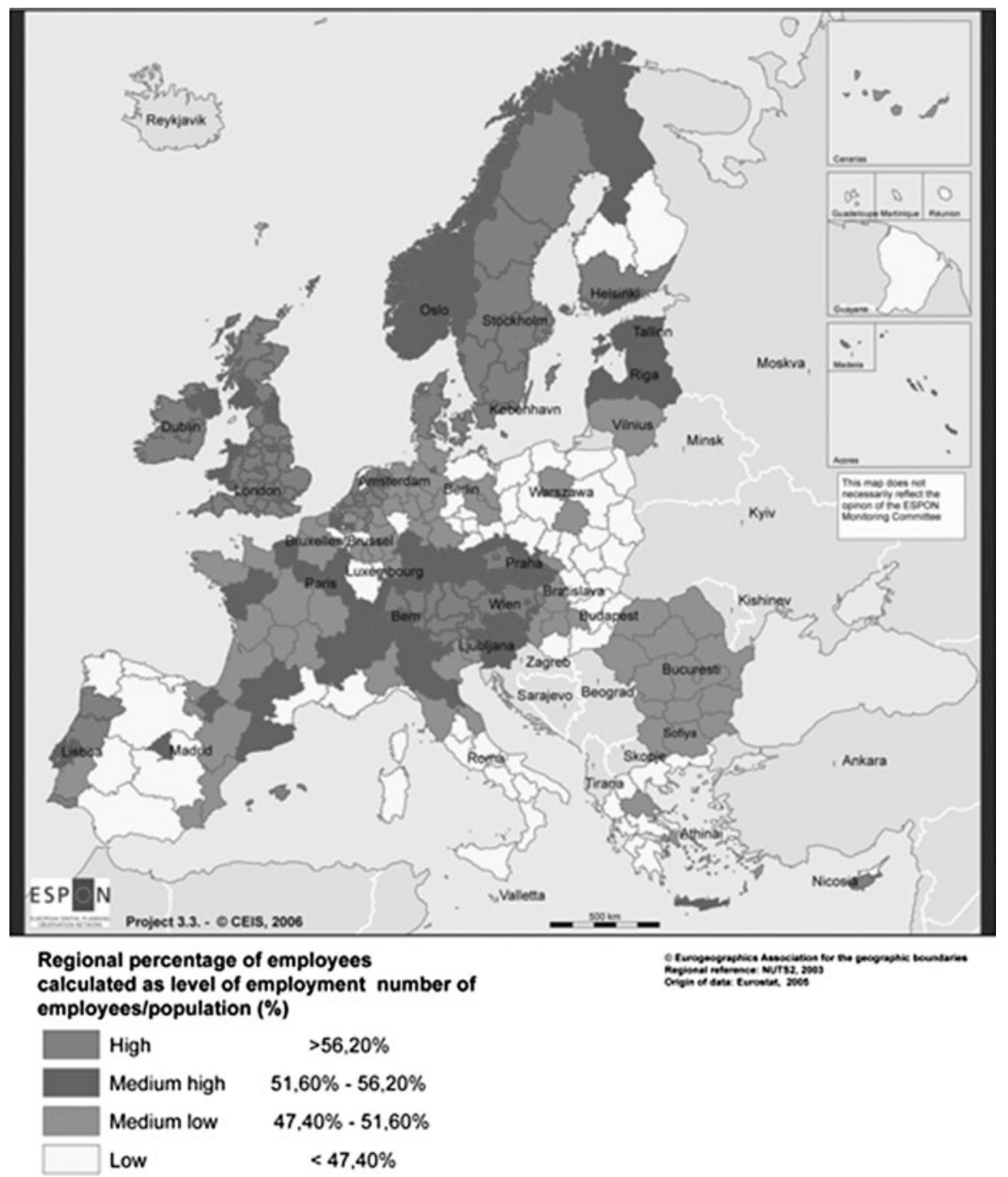

Fig. 3 Employment rate (Prezioso 2006a)

At the same time, the GDP per capita (measured in standard purchasing power) was recording positive values only in northern Italy, western Austria, BadenWürttemberg, Westphalia, Flanders, in the south of the Netherlands and in the dorsal part of the European Central, mostly inclined to the new economy (Fig. 4).

Between 2004 and 2006, and again in 2008-2010, the fourth and fifth Cohesion Report (European Commission 2007, 2010) warned off from the consequences on growth and employment that could have appeared in Europe. In the meantime, Europe was expanding to 25 and then to 27 and would have continued to support, at least until 2013, the entire system with the contribution of only 15 countries to counteract evident imbalances like the high rate of unemployment of the new: it's 


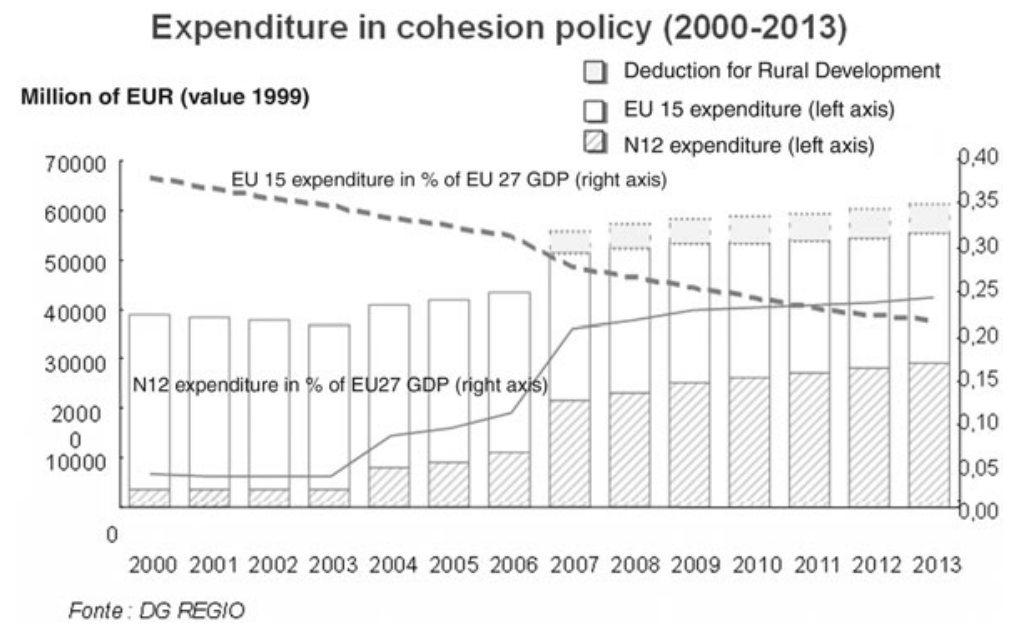

Fig. 4 Expenditure in cohesion policy, 2000-2013 (DG REGIO 2012)

the case of the Cohesion Fund, amounting to $€ 336$ billion (the value has been fixed in 2000 and amounted to the $34 \%$ of the entire EU budget in 2004), which are reallocated 50 and 50 to the old and new member states.

The absence of economic Geography can be noticed in every aspect of European politics of the moment and the case of the Kok Report on Competitiveness in Europe (2004) is illustrative of the dominant address. It stated that endogenous factors would not put a strain on the competitiveness of enterprises (less dominant determinants) but also that the new growth theory (based on neoclassical fundamentals) can be applied to both the regional and the national level.

This vision had already been the subject of criticism by part of the European Commission which considered sustainability at the base of development and, therefore, considered the territory as a measurement parameter of virtuous choices. In fact, the regional and national territory cannot treat/discuss as undifferentiated space of the social and economic action but as a physical place where receive and check the territorial capability of the competitiveness (European Competiveness Report 2003).

Even if ignored, advanced researches (Prezioso 2006a, b) and critical thoughts (Martin 2001; Scott 2009; Rodriguez-Pose 2010) suggested to act on the added value offered by the territorial diversity and its potential of development (the socalled territorial capital). Those studies warned against "destructive and harmful" effects that a fiscal policy, unique and centralized, limited to the solution of problems within the EU, would have generated without a widest economic policy. In addition to the problem of taxation, the policies should have considered the impact on competition of the goods from the Far East countries and of the oil producers (Near East), assessing the status quo of the regions and the European provinces (NUTS 2 and 3) before starting policies of growth, established on the basis of parameters and medians impossible to achieve, finally giving up a top-down approach even if related to an "open coordination". 
The "sin of presumption" that is the basis of common European post-Lisbon policy (2009) did the rest, moving from a blind faith in the power of the so-called three great spheres of the European act: "economic efficiency" (most advanced technologies), "territorial equity" (regional finance and taxation) and "environmental sustainability" (energy) would have required different and specific declinations to the main goals of the economic and territorial development of every country (transport, urban management, rural areas, etc.), in compliance with all the agreements between countries (European Council and Hungarian Presidency 2010; Salamin 2011).

All the disparities (the concept is resumed in the Polish Presidency of the 2011, which raised all its value through the renoved Territorial Agenda), sometimes seeming only apparent but strongly real at lower levels of economic-territorial action (sub-regional and municipal areas), were homologated: this prevented the implementation of the 2013 goals (today postponed to 2020) to be actually effective, equitable and sustainable. Strategic interventions should be implemented by developing sector policies connected with territorial contexts (for example: Agriculture, Enlargement, Environment and Nature, Regional Policy, Transport, Migration, etc.), supported by an appropriate rebalancing and an increasing budget (especially regional), useful for transform the EU priorities into real economic results. However, the request of supporting these strategic interventions have not been concretely taken into account.

After 2008, many geographic conferences, mostly in France, driven by economic and territorial studies, faced the issue of the relationship between crisis and territory, (SCIENCES-PO 2010) bringing it back to:

- some effects of a regional development policy that did not understand the close relationship between cohesion and aménagement du territoire (Faludi 2011). In this context, the need for "good governance" is quoted; the action of the local government in a global perspective, especially looking at the Spanish, French and British best practices, in order to cling to the recovery of southern Europe (PIIGS area).

Today we know that this approach was ineffective, if not harmful, and it proceeded without looking, for example, at the demographic change that would have carried new demands, consumptions and spending (in the case of the Valenciana Comunidad, of the Andalucia and the region of Murcia in Spain, but also the regions of Dublin in Ireland, of Volos in Greece and of the North-East of Italy) (Prezioso 2006a).

Faludi (2011, p. 51) believes that the crisis should be overcome in cohesive terms and also that "geography matters" and that we should "look at the map before implementing policies", quoting the Baltic Sea Strategy which gave a trans-national cooperative response to the global crisis crossing the borders between countries. What Faludi didn't say is that, with the exception of Finland, which had already faced and solved the problem in the past decades, unemployment in the Baltic countries has grown by about $10 \%$ as for Italy (while in Spain it doubled) and, despite this, nothing has changed in setting national targets relying on the efficiency and rigor of the individuals. 


\section{Looking at the Maps}

Looking at the maps, in 2010 the employment rate in the South of Spain, in Italy and in some regions of Romania and Hungary was well below the $70 \%$ (in some cases up to $60 \%$ ), when in many regions of Germany, Great Britain, Netherlands, Denmark, Sweden and Austria it exceeded $75 \%$, that is the average rate to achieve, even in qualitative terms, according to the targets set for 2020 with regard to the population between 20 and 64 years (Monfort 2011).

As in other transition moments, expenditures on Research and Development (R\&D) are taken as an indicator (Fig. 5) to assess the national and the regional ability to invest in growth, but also to measure the distance of legging regions from target-goals and the impact that the high value common policies (see program

\section{Percentage points difference}

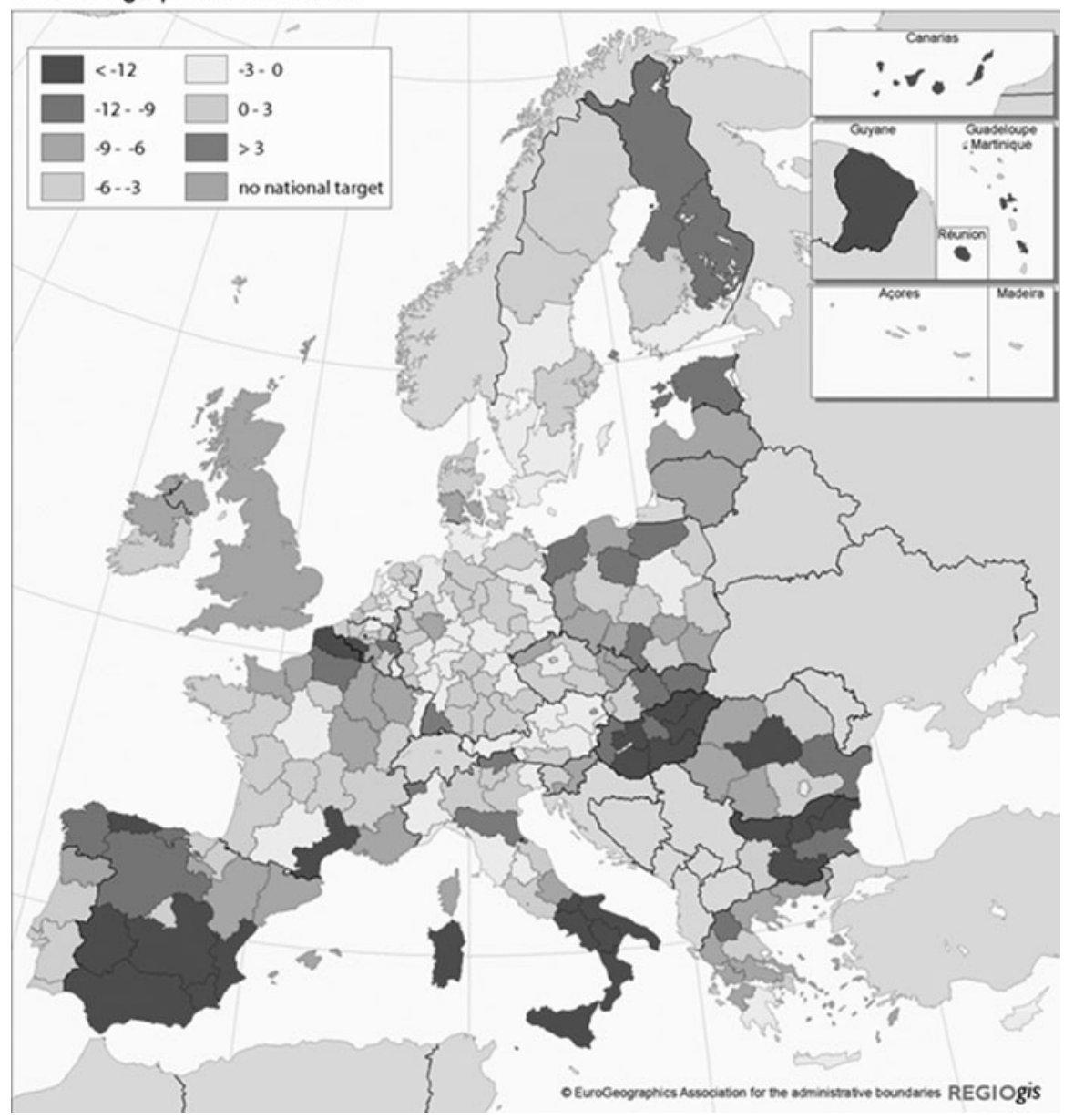

Fig. 5 Employment rate, 20-64, in 2010-distance to national 2020 target (Monfort 2011) 


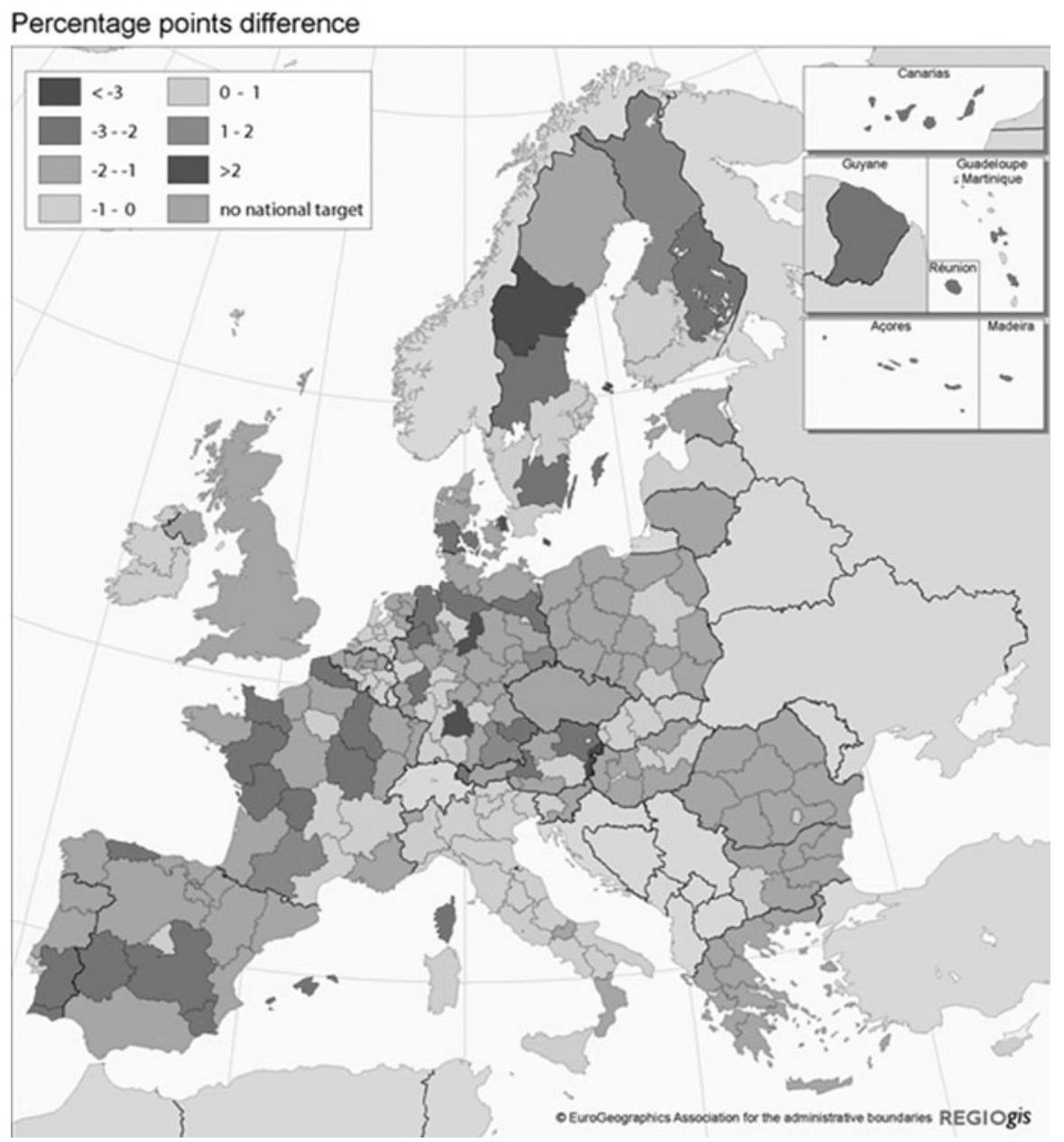

Fig. 6 Total expenditure on R\&D, 2008-distance to national 2020 target (Monfort 2011)

Horizon 2020) could have on the European Spatial Development Perspective (ESDP, the third, still under definition).

For many countries and regions, allocating investments in R\&D means having started a significant spending review at least since 2010, as in the case of Great Britain. However, this is not enough if we consider the level of education reached by the European population between the ages of 30 and 34 (Fig. 6). And certainly we cannot expect in a short-term that the protection measures of the Euro, that the European Central Bank (ECB) is developing and will go on to develop in the next years to achieve full monetary unit, may affect this direction.

Also Jean Tirole (2012) seems to have the opinion that the Eurozone crisis has a "dual" nature (2012) of debt and competitiveness, without forgetting the weakness of the European institutions. 
The Union is an "aging region" in every sense, in opposition to China, India and US, where sovereign countries (with the exception of the capitals) are hardly willing to give up their dominant cultural patterns and where the regional economy has a strong influence on the ability to relate the local with the global, also in terms of education. This last consideration also explains why some regions in Italy (as for Emilia Romagna_-before the earthquake_-Valle d'Aosta and Friuli Venezia Giulia that invested heavily in tertiary technique education) seem to less suffer the effects of the crisis. It also explains the reason why regions with the highest rate of employment in the manufacturing sector (including Germany) have been affected by recession of employment only in the latter period.

The reaction to the crisis' effects in the industry was initially very different: countries such as Germany, the Netherlands, Sweden and Finland seemed to have reacted positively, having implemented policies of innovation and integration between productive sectors since 2007. These countries have limited the employment in services, focusing on quality and efficiency, employing the "temporary support" guaranteed by the Structural Funds 2006, in opposition to Portugal, Spain, Ireland, Italy and Greece, indicated for failing to act on the 12 pillar of competitiveness reported by the World Economic Forum in 2009: institutions, infrastructure, macroeconomic stability, high education and training, market efficiency goods and merchandise, efficiency of the labor market, financial market sophistication, technology, market size, business sophistication, innovation, all intertwined. Once again, it is a mark of the lack of unity of the European system and the permanence of forms of implicit protectionism, beyond the Euro, in the economic policy of the States, as evidenced by the great attention given to the "financial spread" in the last year.

We could simply say that the economy has 'recognized' the crisis, when the crisis war already evident and irreversible, focusing on the values of the debt of the South rather than central-northern Europe, imputing their high rate to a lack of competitiveness. Besides, geography and economic Geography have realizedbut not analyzed - the crisis in decisive terms. At the moment, both of them miss the epistemological capacity to understand that this long-term crisis is not only due to the debt, the speculation and the disbelief of markets, but to the problems of a European Union far from the political cohesion and, therefore, more dependent on national policies variables and on the euro's performance.

A slow growth with low rates of productivity and demand in southern Europe has certainly triggered the current economic recession that preceded the hardest recent crisis. In countries like Italy, Spain, Greece and Portugal, symptoms were obvious: economic activities were increasingly tied to specific contexts (many were considered as "success stories" from business economics), providing positive externalities (post-Fordism) also to the public policy, ignoring the value of internality.

Public investments, realized in most of cases through the Structural Funds, have almost never been directed and measured on the demand (infrastructure, innovation, energy, etc.). Filtered since the 2009 by the European policy of fiscal restraintsometimes even from ideological myopia of central and local governments-public investments have minimized the importance of existing resources in the regions, 


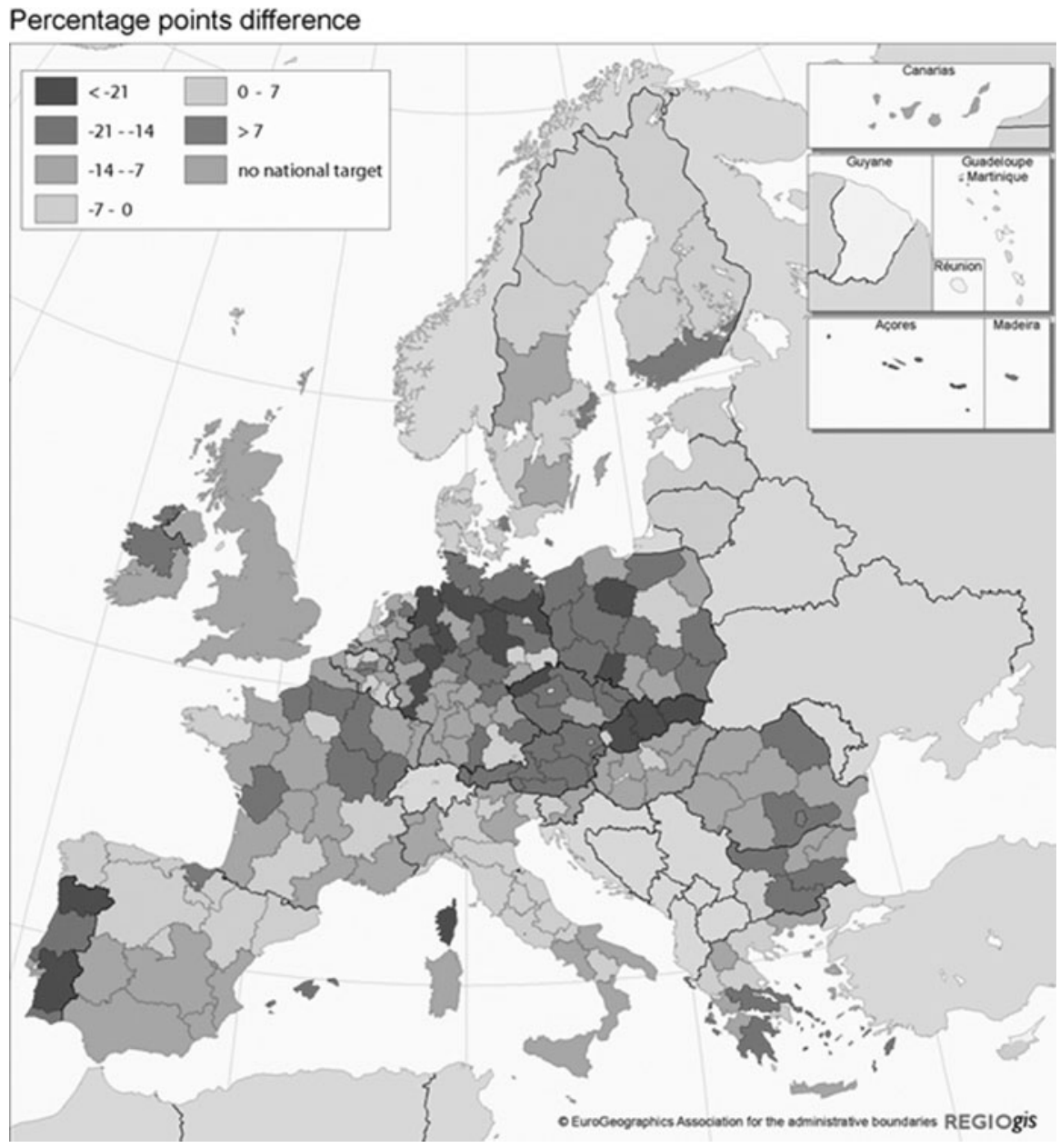

Fig. 7 Population aged 30-34 with a tertiary education-average 2007/10_-distance to National 2020 target (Monfort 2011)

aiming indeed to remetropolitisation and reconcentration of economic activities in these areas already equipped with the necessary framework conditions (Fig. 7).

Keynes certainly cannot be seen as the theoretical reference of these actions. A mix of Schumpeter and the neo-Schumpeterian, of the effects of the "new growth theory" (use of highly professionalized human capital) and of many other theories (from the institutionalist to the evolution theory, the cluster one, etc.), depending on the country, created a too complex melting pot of approaches for a unitary system as the EU (Fig. 8).

The only themes that aggregate are the fiscal and the monetary policy. It is what all the ministers of finance had been aiming from 2009 to present, working on one side on the levy, unable to act on the devaluation of the euro, and on the other side on the constant reminding to the rules, including the application of sanctions. 


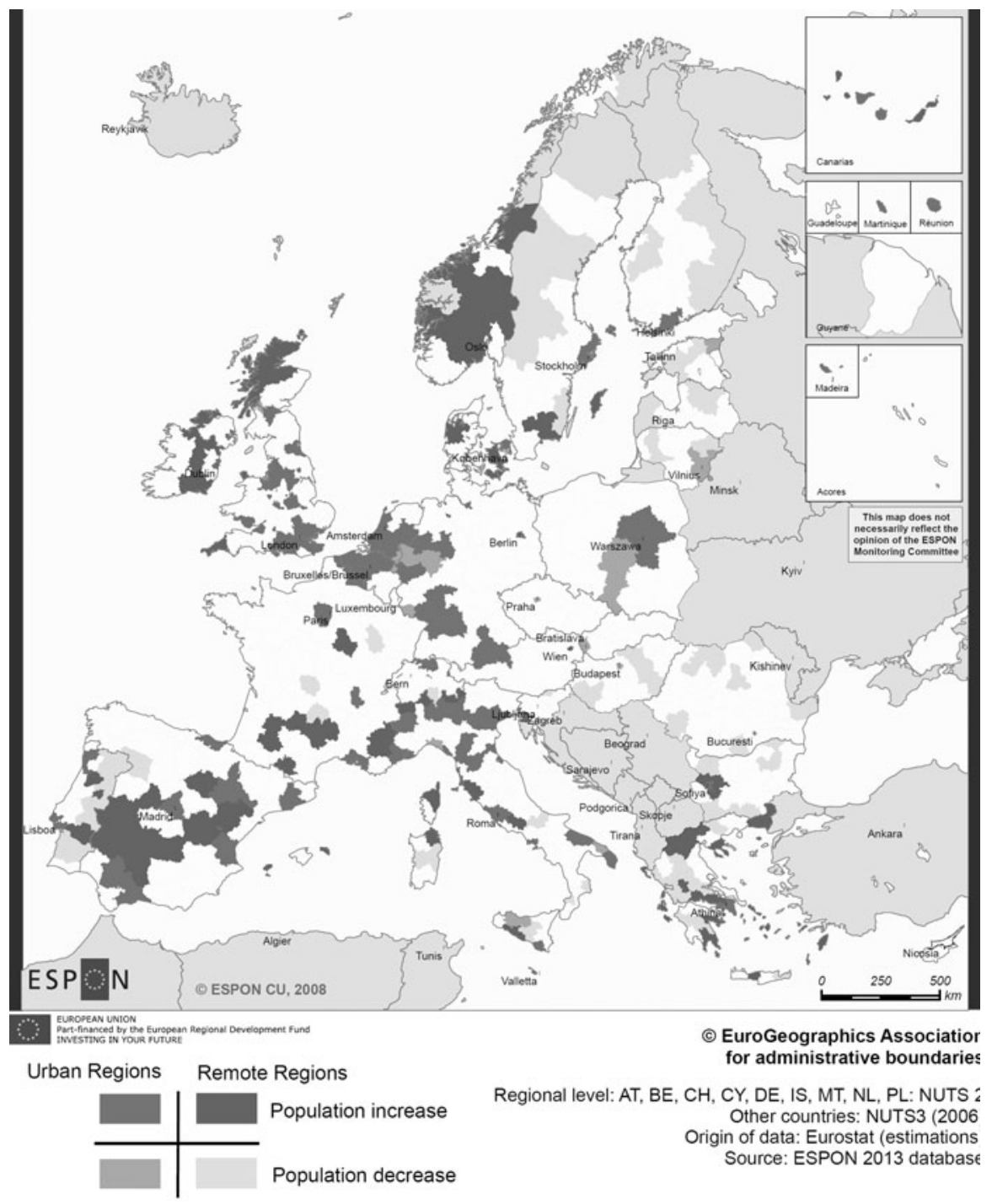

Rural/intermediate regions close to a city

no data

Fig. 8 Population growth in urban and remote regions (ESPON 2008)

\section{The Case of Italy}

Some studies, carried out on several occasions between 2004 and 2011 on the regions and the Italian provinces (Prezioso 2006b, 2011) highlighted these considerations in Italy, underlining, before and during the initial stages of the crisis, the undesired economic and territorial effects of the European policy 
implemented through the Structural Funds of 2006 and 2013. Those interventions, almost all the time, tend to "chase" and not to support the competitiveness and innovation of production systems, both in economic transition (Piedmont) or already settled (Lombardy), or to support sustainability in activities considered "safe" and attractive like energy, tourism or hosting of large events (Valle d'Aosta, Lombardy, Lazio).

In this period we can notice a strong reconcentration of some systems always considered as urban (Turin), decentralizing the high functional specialization in emerging centralities where the identity and the productive cohesion are more evident (for example Brescia).

It is exactly in these medium-small size realities that we can remark the improvement of the banking and of the financial system, of insurance, of business and high-tech networks which are combined with the attention to urban quality, to the environment and the citizens' participation, noting a positive performance in the consumption of the so-called "other economy", in waste's treatment, in the cultural and touristic interaction.

The remetropolisation is consolidating in large urban areas (Milan-BergamoBrescia, Bologna-San Lazzaro, Venice-Padua) outlining a polycentric model as for the Adria Po Valley and a shared path planning, attending to reach the high performance of the global Functional Urban Areas (FUA) of central Europe.

This doesn't mean a loss of centralities as for Turin, Milan, Bologna, Rome, which continue to represent a landmark for provision of infrastructure, potential of research and development, quality of life, use of funds, attraction of tourists, students and financial flows.

Actually, it represents a split in the correlation between regional performance (generally low) and urban influence (generally high). There is a progressive worsening of an already small competitive ability, as for the areas of the Central and the South Central (Tuscany, Lazio, Campania-with the exception of Florence and Rome) due to the 'fracture' among urban, inland and suburban areas with rural connotation, where anthropogenic uses are only in urban systems, with an apparent weaknesses in outsourcing of production system, in the accessibility and the diffusion of innovation, despite the access to EU funds and the presence of major research institutes.

The measure of this state, defined as the absence of internal (regional) and external (national, towards the EU) cohesion, has limited the expected results (effectiveness) in the use of resources, despite the availability of national and European aid for the regions of the Centre-South (Umbria, Lazio, Abruzzo, Molise, Campania)—beyond the catastrophic events that overtook the country in the recent years.

The lack of regional, national and European cohesion became "infectious": it has quickly spread and branched (i.e. the Adriatic area), disrupting those processes aimed at an integrated occupation (aging and inflexible population, micro entrepreneurial dimension) in the leading sectors of the Italian economy.

It comes as no surprise that in Italy, just at the beginning of the crisis and on the push of the EU, there has been a significant growth of expenditures of the public administration in the development of regional GDP (health, education, local government), balancing the national outlays concentrated on the military spending 
which guaranteed the participation of the country to the great actions of international politics between 2008-2010.

To set off the negative effects that this process produced, the Italian regional economy pointed at the exports of traditional sectors, in the short term, stressing the already existing trend of outsourcing and of a low diversification, excluding the less accessible mountain and rural areas.

The Southern regions were particularly weakened by these processes, making even more obvious, in front of the EU, the instability of the economy and the employment in regions such as Basilicata, Calabria, Sicily, Sardinia, triggering urgent requests of cohesive policies based on flexibility and labor mobility, on energy and waste recycling, on technological innovation for business and social integration, to tie to the efficiency of the network infrastructure.

The regions with a long-term attitude of social cohesion (such as Valle d'Aosta) have obviously reacted by focusing on their potential and reducing investment in ICT and R\&D, which turned higher in regions where support for social cohesion failed (Piedmont, Lombardy, Emilia Romagna, Marche).

Obviously, it is impossible to pursue standardizing actions (convergence) to raise the growth in Italy because it assumes an ambiguous connotation in the lagging regions, as shown by the empirical evidence. As an example, it can be underlined a labor market that is unfocused on the economic and the social inclusion of potentially active workforce between the ages of 55 and 64, in the North of Italy (but also in Slovenia and Austria), in favor of the younger labor force that chooses not to continue in higher education (more than $30 \%$ in Italy, Spain and Luxembourg).

The gross domestic expenditure on R\&D (identified in Europe by the acronym GERD) has a low value in many European regions with old industrialization, not only in Italy: in our country, this expenditure is paying the price of the low per capita productivity, which is expected to reach in 2010 the $3 \%$ of GDP dedicating two-thirds of it to the private sector (aerospace, transportation technology, etc.).

Therefore, it's necessary to implement policies of stabilization of economic and territorial contexts. First of all it's to consider the prices' policy (before the crisis, prices in Italy were in line with the European average and did not differ more than $7 \%$ ), especially in regions with low productivity in the South of Italy, in order to counter the unequal distribution of productivity, the decrease of specialization and the purchasing power of wages with the contraction in consumption.

If fact, productivity is not correlated with the employment rate in some regions of Southern Italy and Europe (France, Greece, Spain) like Sicily, Calabria, Campania: in 2006, these regions were showing productivity rates higher than the European average, but low levels of employment, opposite to Germany, Fennoscandia and Switzerland, whose rates of long-term unemployment were similar to the one registered in the German lënder born after unification.

\section{How to Keep Going?}

Since 2006, the socio-economic and territorial polycentrism outlines, on one hand, the possible solution to the need for fairness and, on the other hand, the efficiency of 
states and regions. However, the European territorial diversity requires different solutions within a same policy, where mechanisms for the redistribution of monetary actions can be triggered automatically.

This can be guaranteed only by federalism, to which the polycentric of the European system can be considered a useful first step in order to clarify:

- which organization (including the fiscal one), vertical and horizontal, could be more appropriate to raise, in a sustainable manner, the ability to compete;

- how and where this corema is expression of subsidiary cohesion to achieve balanced forms of socio-economic development in the medium term.

Shortly, polycentrism may be, at this time, a good substitute for the still difficult to imagine political-constitutional and fiscal federalism, to ensure rigor and not austerity.

Regional and economic-territorial relativism (present in the Italian culture since the end of the Eighteenth century, it bound with the problem of regional but also more particularly 'Southern Question'), overlooking the polycentrism, connects to the capabilities that the regions have to produce and to move flows of-even modest-production towards development.

In this way, European federalism (that is understood by economists as a territorial articulation of powers and of government levels doesn't need to exist but there would be a specific geographical limit guiding the interpretation of the crisis: the state acquires its visible body (territory and geo-economic landscape) with many regional forms, different in type and level, preventing to keep the implicit character of supra-nationalism (the impossible status quo) unchanged, implicit when the European Union was founded and whereby the crisis-but not the austerity-is measuring.

Insightful changes and contradictions that characterized the growth of the European Union from the opening of the single market have highlighted the fact that macro-policies, focused on employment capacity, are opposed to the strengthening of the accumulation capabilities and real growth.

Offering over time certain commercial advantages, supra-nationality has replaced the aim to create a united Europe on territorially cohesive bases, balancing its negative effects with a central action and minimizing the disadvantages that the suburbs bear to be convergent and to access benefits of the euro area, as demonstrated by the increasing values of the intra-Community trade EU-27 (compared to the total trade of the Union): this values-measured by shipmentsgrew by $16 \%$ in 2010 , meaning a lower rate than the one recorded for extra-EU exports (up to $23 \%$ ).

The already described structural indicators are taken by many economists as an example of the level of integration achieved, forgetting that free trade and its expansion produced some initial conflicts on the domestic market (the price war) and on the development of new trading blocks in geographical proximity areas (i.e. Germany-Poland).

At the moment, these blocks do not seem to reduce in number and scope. Indeed, as a result of the crisis and austerity policies implemented also in Italy, they will rise 
up to take the form of oligopolistic regions (the "head-to-head" for the capture of mutual markets).

Countries like Germany could preserve their traditional leadership in manufacturing thanks to the limited external competition in high-tech and electronics, while others, like France, would reinforce their presence in the areas of basic industry and transportation, diversifying the production. Others, like Great Britain, may decrease shares in all sectors except for the trade of services and for agriculture or, like Italy, lose the challenge of high quality mono productive specialization (industrial districts).

In order to ensure the individual financial stability within the EU and the euro zone, it would probably be good to re-examine the effects of the integration process of the stability towards the principle of subsidiarity, which is a pivotal principle both in the common objective of financial stability and in the emerging extended model of polycentrism (new regionalization).

As remarked, the creation of a single market and of a single currency doesn't necessarily reduce the risk of financial instability. A process of integration, based on the agreements established only among the in-countries, may increase that risk if out-countries are excluded from the procedures that regulate the system of debt payments.

In fact, the spatial structure of the Union only partially corresponds to the characteristics of the "state guide", because of the persistence of discontinuities not only physical (the most significant are the ones represented by the Irish Sea, the English Channel, the Alps, the Otranto's channel) but also economic, as those who oppose the Rhine Valley, the British Isles and the Iberian peninsula for density of population, employment in the secondary industry, energy consumption and GDP.

Besides, the anti-European culture in the suburbs has often appeared with strong tones of ignorance or distrust against supranational institutions, while central areas are still not able to express functional characteristics to internationalize the differences.

Therefore, the spatial structure of the European community, as it stands, is dominated by a deep territorial discontinuity that, given the intensity of the crisis and the conditions of settlement, fed the network of national identities and regulations, increasing the differences.

Economic differentials and financial spreads are currently the main obstacles to the homologation of a rigorous political-territorial organizational structure that recurs as a regulatory and institutional diversity.

\section{References}

Barca F (2009) An agenda for a reformed cohesion policy. A place-based approach to meeting EU challenges and expectations. Independent Rep. to D. Hubner. Bruxelles: Commissioner of Regional Policy. http://ec.europa.eu/regional_policy/policy/future/barca_en.htm. Accessed 20 Oct 2012

Bilmes L, Stiglitz JE (2006) Encore. Iraq war will cost more-than-\$2-trillion. Milken Inst Rev 4:76-83 Dijkstra L (2011) Investing in Europe's future. Presentation of the V Cohesion Report. In European Commission Presentation. DG Policy Regio, Bruxelles

ESPON (2006) 3.2 Project: Spatial Scenarios in relation to the ESDP and EU Cohesion Policy. Luxemburg: ESPON 
ESPON (2008) Territorial dynamics in Europe. Trends in population development-territorial observation. ESPON, Luxembourg

European Commission (2004) III Report on Economic and Social Cohesion. Brussels

European Commission (2007) IV Report on economic and social cohesion. Brussels

European Commission (2010) V Report on economic and social cohesion. Brussels

European Council, Hungarian Presidency (2010) Territorial agenda of the European Union 2020. 19 May. Gödöllő: Informal Meeting of Ministers Responsible for Territorial Development

European Council, Polish Presidency (2011) Cohesion policy. Program of the Polish Presidency of the Council of the European Union. Regional Development Ministry, Warsaw

Faludi A (2011) Evolution and future of EU territorial cohesion policy. In Crysis y Territorio, Sexto Congreso Internacional de Ordenación del Territorio. Fundicot, Madrid, pp 41-54

Grasland C (2007) Europe In the world. BRUXELLES: ESPON 2006. http://www.espon.eu/main/Menu_ Projects/Menu_ESPON2006Projects/Menu_CoordinatingCrossThematicProjects/europeintheworld. html. Accessed 22 Oct 2012

Kitson M, Martin M, Tyler P (2011) The geographies of austerity. Camb J Econ Reg Soc 4(3):289-302

Kok W (Eds) (2004) Facing the challenge. The Lisbon strategy for growth and employment. November. Bruxelles

Krugman P (2008) Let's get fiscal. The New York Times 2008. http://www.nytimes.com/2008/10/17/ opinion/17krugman.html? Accessed 3 Sept 2012

Martin R (2001) Geography and public policy: the case of the missing agenda. Prog Hum Geogr 25(2):189-210

Monfort P (2011) The regional and urban dimension of Europe 2020. In Evidence-based cohesion policy: territorial dimensions. ESPON 2013 Programme, Kracow

OECD (2009) How regions grow: trends and analysis. OCSE, Paris

Pettifor A (2006) The coming first world debt crisis. Palgrave, London

Prezioso M (2006a) Territorial dimension of the Lisbon-Gothenburg strategy-final report. Aracne, Rome. http://www.espon.eu/main/Menu_Projects/Menu_ESPON2006Projects/Menu_Coordinating CrossThematicProjects/lisbonstrategy.html. Accessed 15 Sept 2012

Prezioso M (ed) (2006b) Research on territorial cohesion indicators for monitoring 2007-2013 programs in Italy. MIT \& EUKN e-Library, Roma

Prezioso M (2008a) Is it possible to give more relevance at territorial dimension onto competitive and sustainable policy choices? Transit Stud Rev XV(1):1-19

Prezioso M (2008b) The territorial dimension of a competitive governance in sustainability. Boletin De La Asociacion de Geografos Espanoles 46:163-179

Prezioso M (2008c) Cohesion policy: methodology and indicators towards common approach. Rom J Reg Sci $2: 1-32$

Prezioso M (2011) Competitiveness in sustainability: the territorial dimension in the implementation of Lisbon/Gothenburg processes in Italian regions and provinces. Pàtron, Bologna

Rodriguez-Pose A (2010) Economic geographers and the limelight: the reaction to the 2009 World Development Report. Econ Geogr 86(4):361-370

Salamin G (ed) (2011) Territorial Agenda and Territorial State and Perspectives as guiding documents for future of territorial cohesion. VÁTI, Budapest

SCIENCES-PO (2010) Réseau d'études et de recherches sur cohésion et territoire en Europe. Datar, Paris

Scott AJ (2009) World Development Report 2009. Reshaping Economic Geography. J Econ Geogr 9(4):583-586

Tirole J (2012) The euro crisis: some reflections on institutional reform. Financ Stab Rev 16:225-242

Van Hamme G (ed) (2012) Territorial impact of globalization for Europe and its regions. ESPON Program 2013. ESPON \& Université Libre de Bruxelles, Bruxelles

\section{Websites}

ESPON Program (2013) European Observation Network, Territorial Development and Cohesion. www.espon.eu

EUROPEAN COMMISSION (2010) Europe 2020 - a strategy for smart, sustainable and inclusive growth. http://ec.europa.eu/europe2020/index_en.htm 